\title{
Combustion synthesis and characterization of porous perovskite catalysts
}

\author{
YUEHUI WU-LAITAO LUO* and WEI LIU \\ Institute of Applied Chemistry, Nanchang University, 330031 Nanchang, P.R. China \\ e-mail: luolaitao@163.com
}

MS received 21 November 2006; revised 10 March 2007

\begin{abstract}
Porous perovskite-type complex oxides $\mathrm{LaCoO}_{3}$ and $\mathrm{La}_{0.95} \mathrm{Sr}_{0.05} \mathrm{Ni}_{0.05} \mathrm{Co}_{0.95} \mathrm{O}_{3}$ were produced by combustion method. The properties of these porous materials such as crystal structures, particle sizes, surface patterns, pore size, surface area and pore volume were characterized by X-ray diffraction( XRD), scanning electron microscopy(SEM) and BET measurements. The results indicated that all porous materials are of the perovskite-type complex oxides. Doping $\mathrm{Sr}^{2+}$ ions on site $\mathrm{A}$ and doping $\mathrm{Ni}^{2+}$ ions on site $\mathrm{B}$ entered the crystal lattices of $\mathrm{LaCoO}_{3}$ in the place of $\mathrm{La}^{3+}$ and $\mathrm{Co}^{3+}$, respectively, and the maximum peak of XRD patterns of doping sample was weaken and broaden. Morphological microscopy demonstrated agglomerates involved mostly thin smooth flakes and layers perforated by a large number of pores and its lamella decreased with the introduction of $\mathrm{Sr}^{2+}$ and $\mathrm{Ni}^{2+}$. Hysteresis loop in the $\mathrm{N}_{2}$ adsorption-desorption isotherm of samples indicated its porous structures and the doping effect on its pore size, surface area and pore volume were improved. The porous catalysts have been tested for methane catalytic combustion and the results showed that these catalysts possessed high catalytic activity.
\end{abstract}

Keywords. Combustion method; porous perovskite catalysts; methane; catalytic combustion.

\section{Introduction}

Most of catalysts used in the modern chemical industry are the catalyst of complex oxides. Among many available complex oxides materials, perovskite-type complex oxides which have the same structure as natural $\mathrm{CaTiO}_{3}$ (generally in its orthorhombic form) are particularly noticeable. ${ }^{1-4}$ perovskite-type complex oxides materials are more and more favoured in many fields due to its design flexibility. ${ }^{4-7}$ But those perovskite-structural complex oxides produced via conventional synthesis methods are found to be with relatively low specific surface areas and low catalytic activity in the reactions, thus its commercialised applications are limited. So it is very important for us to develop a new method to prepare the kind of catalytic materials with large specific surface area values. Porous perovskite-type complex oxides have been recently studied as new catalytic materials for their large specific surface area values, low cost, high catalytic activity and high stability ${ }^{8,9}$. To our knowl-

*For correspondence edge, here we report for the first time the obtaining of the porous perovskite-structural complex oxides materials by sol-gel combustion method, which were characterized by some measurements.

\section{Experimental}

\subsection{Catalyst preparation}

The catalysts, $\mathrm{LaCoO}_{3}$ and $\mathrm{La}_{0.95} \mathrm{Sr}_{0.05} \mathrm{Ni}_{0.05} \mathrm{Co}_{0.95} \mathrm{O}_{3}$, were prepared by citric acid sol-gel combustion synthesis method. Briefly, lanthanum, strontium, nickel and cobalt nitrates in a desired molar ratio were dissolved in a citric solution at room temperature with constant stirring. At pH 6-7 (ammonia adjustor), acrylamide and other organic crosslinking agent were added in the solution, then the mixer was heated to $90-95^{\circ}$. The stirring was continued until a gel was formed. Then the prepared gel were transferred into a ceramic dish and placed into an oven preheated at $350^{\circ} \mathrm{C}$, and then the combustion reactions could be carried out. With the temperature-increasing rate of $2 \square \bullet \min ^{-1}$, the obtained precursor was calcined at 700 or $750^{\circ} \mathrm{C}$ for $2 \mathrm{~h}$. 


\subsection{Characterization}

Powder X-ray diffractometer (type D-Max-3B made in Japan) over the range $20^{\circ} \leq 2 \theta \leq 80^{\circ}$, at room temperature, operated at $40 \mathrm{kV}$ and $100 \mathrm{~mA}$, using $\mathrm{CuK} \alpha$ radiation combined with the nickel filter, scanning rate of $0.5^{\circ} \mathrm{min}^{-1}$. Scanning electron micrographs of the powders were obtained using a JEOL JSM-5800, scanning electron microscope. BET specific surface areas were measured by nitrogen adsorption-desorption at $78 \mathrm{~K}$ using a Micromeritics ASAP 2020 instrument.

\subsection{Measurement of catalytic activities}

The $\mathrm{CH}_{4}+\mathrm{O}_{2}$ reactions were carried out in a flow microreactor by feeding a gas mixture of $\mathrm{CH}_{4}$ (1.0 vol.\%), $\mathrm{O}_{2}\left(10.0\right.$ vol.\%) and $\mathrm{N}_{2}$ (balanced) over $100 \mathrm{mg}$ catalyst with $20,000 \mathrm{~h}^{-1}$ GHSV and 300 $700^{\circ}$ reaction temperature. The gas composition was analysed before and after the reaction by an online gas chromatography with thermal conductor detector (TCD), which was connected with a computer integrator system and Porapak Q columns was used. The activity of the catalysts was assigned as conversion.

\section{Results and discussion}

\subsection{XRD measurement}

$\mathrm{LaCoO}_{3}$ (sintered at $700^{\circ}$ for $2 \mathrm{~h}$ ) and $\mathrm{La}_{0.95} \mathrm{Sr}_{0.05}$ $\mathrm{Ni}_{0.05} \mathrm{Co}_{0.95} \mathrm{O}_{3}$ (sintered at $750^{\circ}$ for $2 \mathrm{~h}$ ) mixed oxides was prepared by sol-gel combustion synthesis method and its XRD patterns are presented in figure 1. The results of phase analysis in figure 1 clearly show that the XRD patterns of $\mathrm{La}_{0.95} \mathrm{Sr}_{0.05} \mathrm{Ni}_{0.05}$ $\mathrm{Co}_{0.95} \mathrm{O}_{3}$ had the same direction as those of $\mathrm{LaCoO}_{3}$, such as (110), (020), (112), (220) and (130) peaks thus it can be concluded that both $\mathrm{LaCoO}_{3}$ and $\mathrm{La}_{0.95}$ $\mathrm{Sr}_{0.05} \mathrm{Ni}_{0.05} \mathrm{Co}_{0.95} \mathrm{O}_{3}$ are perovskite-structural complex mixed oxides and no uncertain phase could be discovered. Meanwhile, it also is found that the peak locations of samples $\mathrm{La}_{0.95} \mathrm{Sr}_{0.05} \mathrm{Ni}_{0.05} \mathrm{Co}_{0.95} \mathrm{O}_{3}$ remained intact with the introduction of $\mathrm{Sr}^{2+}\left(r_{\mathrm{Sr}}^{2+}=\right.$ $0.1310 \mathrm{~nm})$ and $\mathrm{Ni}^{2+}\left(r_{\mathrm{Ni}}^{2+}=0.124 \mathrm{~nm} ; r_{\mathrm{Ni}}^{3+}=0.074 \mathrm{~nm}\right)$, this implies the completion of crystallization and doping $\mathrm{Sr}^{2+}$ ions on site $\mathrm{A}$ and doping $\mathrm{Ni}^{2+}$ ions on site $\mathrm{B}$ entered the crystal lattices of $\mathrm{LaCoO}_{3}$, which replace $\mathrm{La}^{3+}\left(r_{\mathrm{La}}^{3+}=0.1216 \mathrm{~nm}\right)$ and $\mathrm{Co}^{3+}\left(r_{\mathrm{Co}}^{2+}=\right.$ $\left.0.125 \mathrm{~nm} ; r_{\mathrm{Co}}^{3+}=0.075 \mathrm{~nm}\right)$. But the maximum peak of XRD patterns of doping sample is weaken and broaden, and indicates that samples $\mathrm{La}_{0.95} \mathrm{Sr}_{0.05}$ $\mathrm{Ni}_{0.05} \mathrm{Co}_{0.95} \mathrm{O}_{3}$ are single phase with more rhombohedral distorted perovskite structure than undoped samples $\mathrm{LaCoO}_{3}$.

\subsection{Surface area and porous structure}

The results for the nitrogen isothermal sorption at $78 \mathrm{~K}$ of $\mathrm{LaCoO}_{3}$ and $\mathrm{La}_{0.95} \mathrm{Sr}_{0.05} \mathrm{Ni}_{0.05} \mathrm{Co}_{0.95} \mathrm{O}_{3}$ perovskite-type mixed oxides are presented in figure 2, respectively. All the isothermal results show hysteresis loops, whose characteristics exhibit dependence on the structure of the samples, which are confirmed to be with a porous morphology. Such isothermal curves exhibit a intermediate profile between type B and
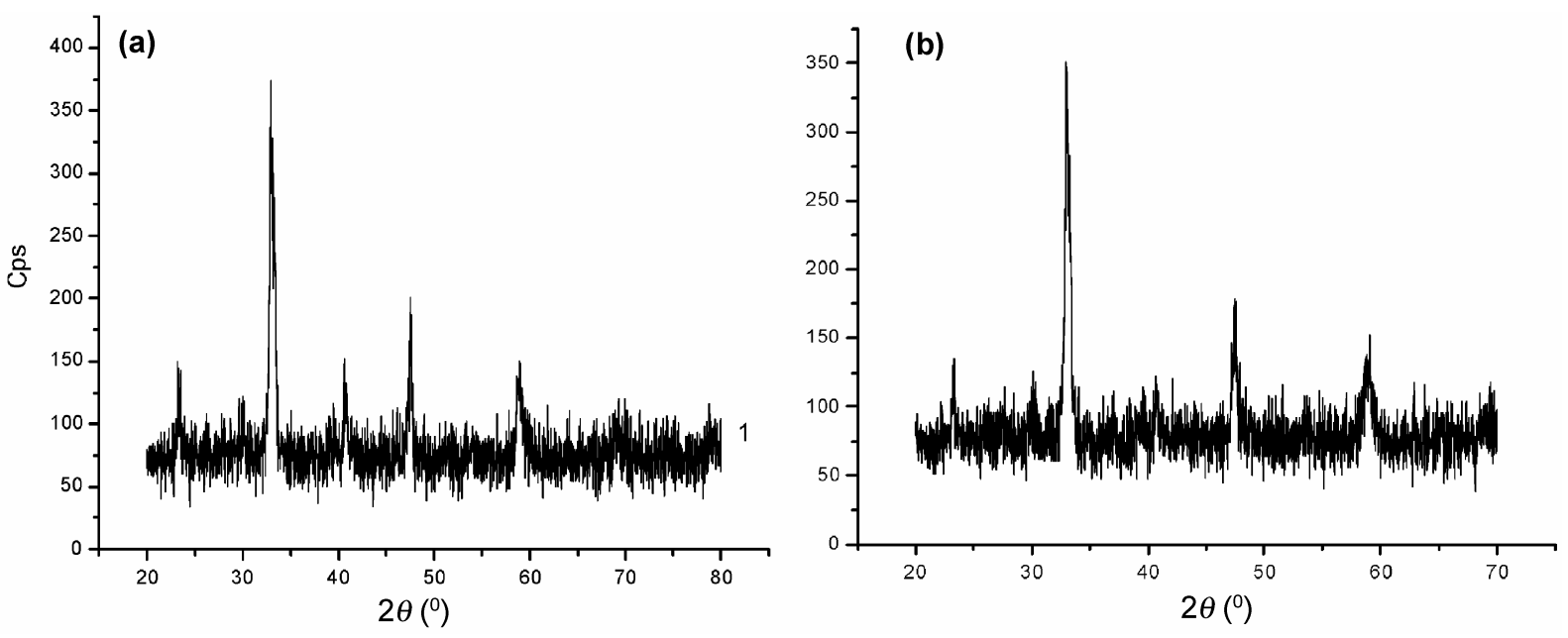

Figure 1. XRD patterns of $\mathrm{LaCoO}_{3}$ and $\mathrm{La}_{0.5} \mathrm{Sr}_{0.05} \mathrm{Ni}_{0.05} \mathrm{Co}_{0.95} \mathrm{O}_{3}$. a. $\mathrm{LaCoO}_{3}$. b. $\mathrm{La}_{0.95} \mathrm{Sr}_{0.05} \mathrm{Ni}_{0.05} \mathrm{Co}_{0.95} \mathrm{O}_{3}$. 

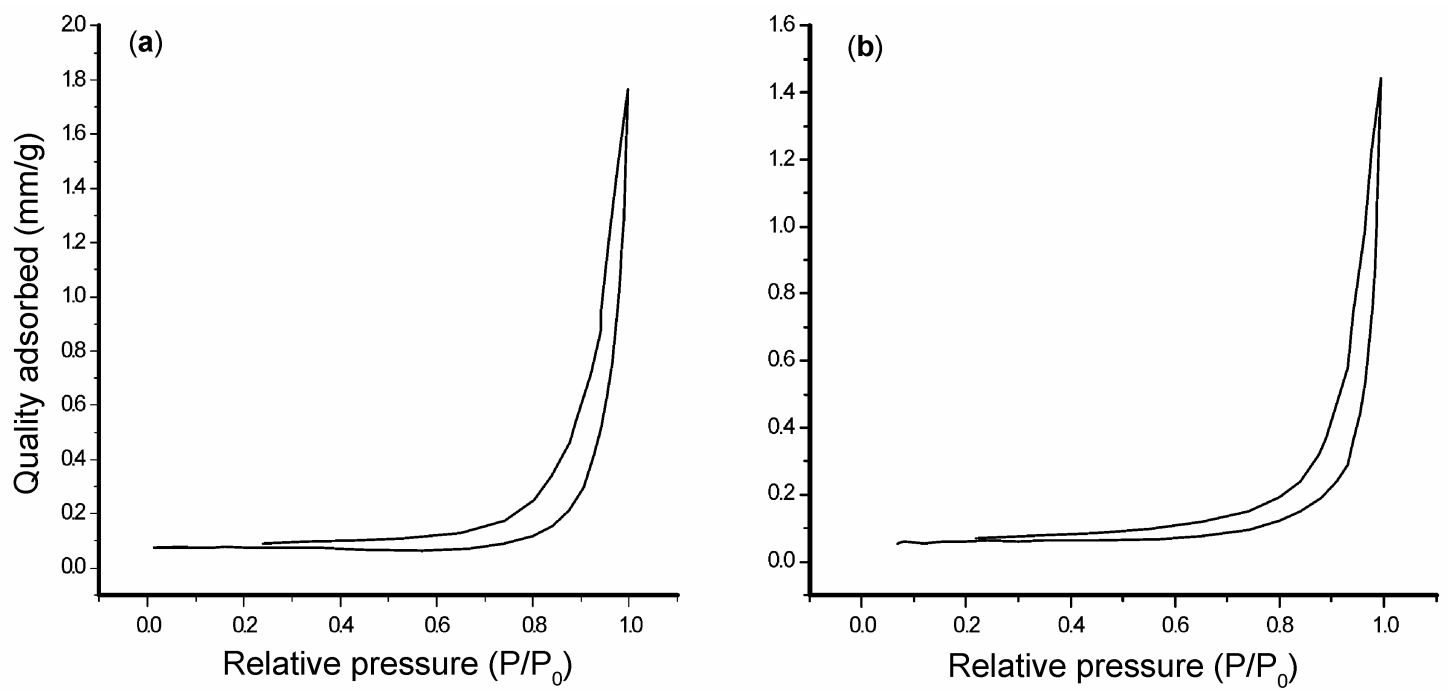

Figure 2. $\mathrm{N}_{2}$ adsorption-desorption isotherm of $\mathrm{LaCoO}_{3}$ and $\mathrm{La}_{0.95} \mathrm{Sr}_{0.05} \mathrm{Ni}_{0.05} \mathrm{Co}_{0.95} \mathrm{O}_{3}$. a. $\mathrm{LaCoO}_{3}$ b. $\mathrm{La}_{0.95} \mathrm{Sr}_{0.05} \mathrm{Ni}_{0.05} \mathrm{Co}_{0.95} \mathrm{O}_{3}$.

Table 1. Characteristics of different catalysts samples

\begin{tabular}{lccccc}
\hline Samples & \multicolumn{2}{c}{$\begin{array}{c}\text { Average pore size } \\
(\mathrm{nm})\end{array}$} & $\begin{array}{c}\text { BET surface area } \\
\left(\mathrm{cm}^{2} / \mathrm{g}\right)\end{array}$ & $\begin{array}{c}\text { Pore volume } \\
\mathrm{T}_{10}(\square)\end{array}$ & $\begin{array}{c}\mathrm{CH}_{4} \text { oxidation } \\
\mathrm{T}_{90}(\square)\end{array}$ \\
\hline Porous $\mathrm{La}_{0.95} \mathrm{Sr}_{0.05} \mathrm{Ni}_{0.05} \mathrm{Co}_{0.95} \mathrm{O}_{3}$ & $43 \square 65$ & 33.6 & $0 \cdot 16$ & 399 & 628 \\
Porous $\mathrm{LaCoO}_{3}$ & 45.39 & 25.4 & $0 \cdot 15$ & 418 & 643 \\
Ordinary $\mathrm{LaCoO}_{3}{ }^{10}$ & - & $5 \cdot 6$ & - & 560 & 750 \\
\hline
\end{tabular}

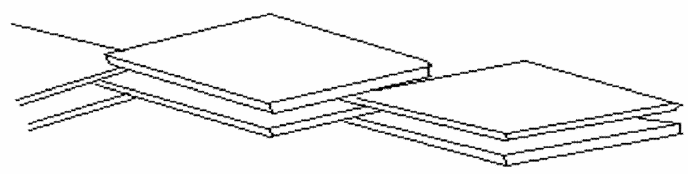

Figure 3. Lamella-structural model of the porous materials.

type $\mathrm{D}$, main typical of lamella structure perforated by a large number of pores. In the other hand, the isothermal curves of samples $\mathrm{LaCoO}_{3}$ and $\mathrm{La}_{0.95}$ $\mathrm{Sr}_{0.05} \mathrm{Ni}_{0.05} \mathrm{Co}_{0.95} \mathrm{O}_{3}$ show a slow increase at the relative pressure $P / P_{0}=0 \cdot 25-0 \cdot 9$, this indicates that the samples has a broader pore-size distribution. Lamella-structural model of the porous materials is presented in figure 3 .

In table 1 some BET data of the samples are presented. The BET results show the surface area of the porous samples, which are prepared by citric acid sol-gel combustion synthesis method, are much larger than that of the samples prepared via conventional synthesis routes. The results also show that the surface area and the pore volume of the porous samples increase with the introduction of $\mathrm{Sr}^{2+}$ and $\mathrm{Ni}^{2+}$, But the average pore size decrease slightly. These results indicate that the introduction of $\mathrm{Sr}^{2+}$ and $\mathrm{Ni}^{2+}$ in the system can increase the surface area of the catalysts with high porosity and inhibit the congregating process.

\subsection{SEM micrographs}

Selected microstructures of samples $\mathrm{LaCoO}_{3}$ and $\mathrm{La}_{0.95} \mathrm{Sr}_{0.05} \mathrm{Ni}_{0.05} \mathrm{Co}_{0.95} \mathrm{O}_{3}$ are presented in figure 4 and 5 , respectively. As shown in figure 4, undoped $\mathrm{LaCoO}_{3}$ perovskite-type mixed oxides is porous and plate-shaped, and the grain size is $\sim 3.0 \mu \mathrm{m}$. However, As shown in figure 5 , the samples $\mathrm{La}_{0.95}$ $\mathrm{Sr}_{0.05} \mathrm{Ni}_{0.05} \mathrm{Co}_{0.95} \mathrm{O}_{3}$ mixed oxides with $0.05 \% \mathrm{Sr}$ and $0.05 \% \mathrm{Ni}$ doping has a slightly bigger crystallite size $(\sim 6.0 \mu \mathrm{m})$.Meanwhile, morphological microscopy of the explored samples also demonstrated agglomerates involved mostly thin smooth flakes and layers perforated by a large number of pores. The crystallite size has increased from $\square 3.0 \mu \mathrm{m}$ to $\square 6.0 \mu \mathrm{m}$ whereas the surface area has enhanced from $25.4 \mathrm{~m}^{2} / \mathrm{g}$ to $33.6 \mathrm{~m}^{2} / \mathrm{g}$ 

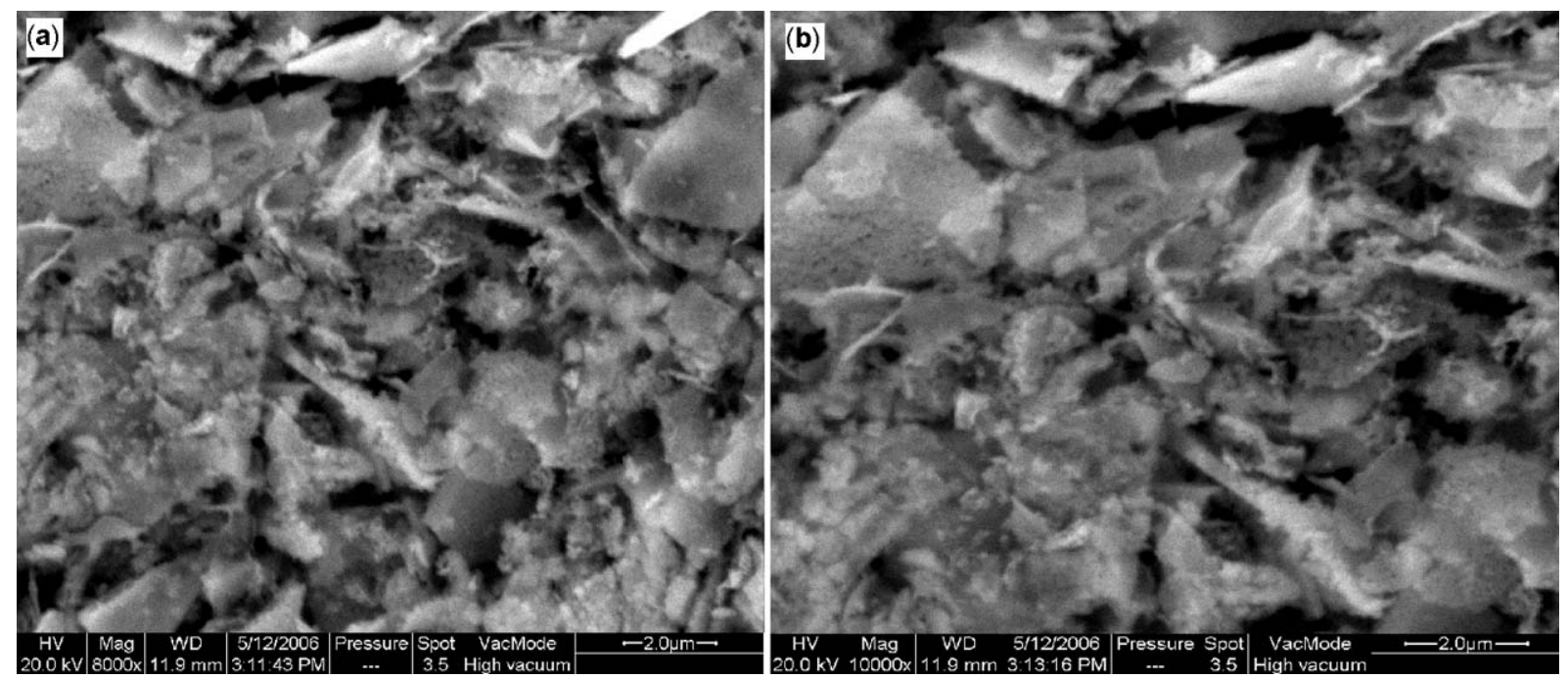

Figure 4. SEM patterns of samples $\mathrm{LaCoO}_{3}$. a. 8000 times; b. 10000 times.
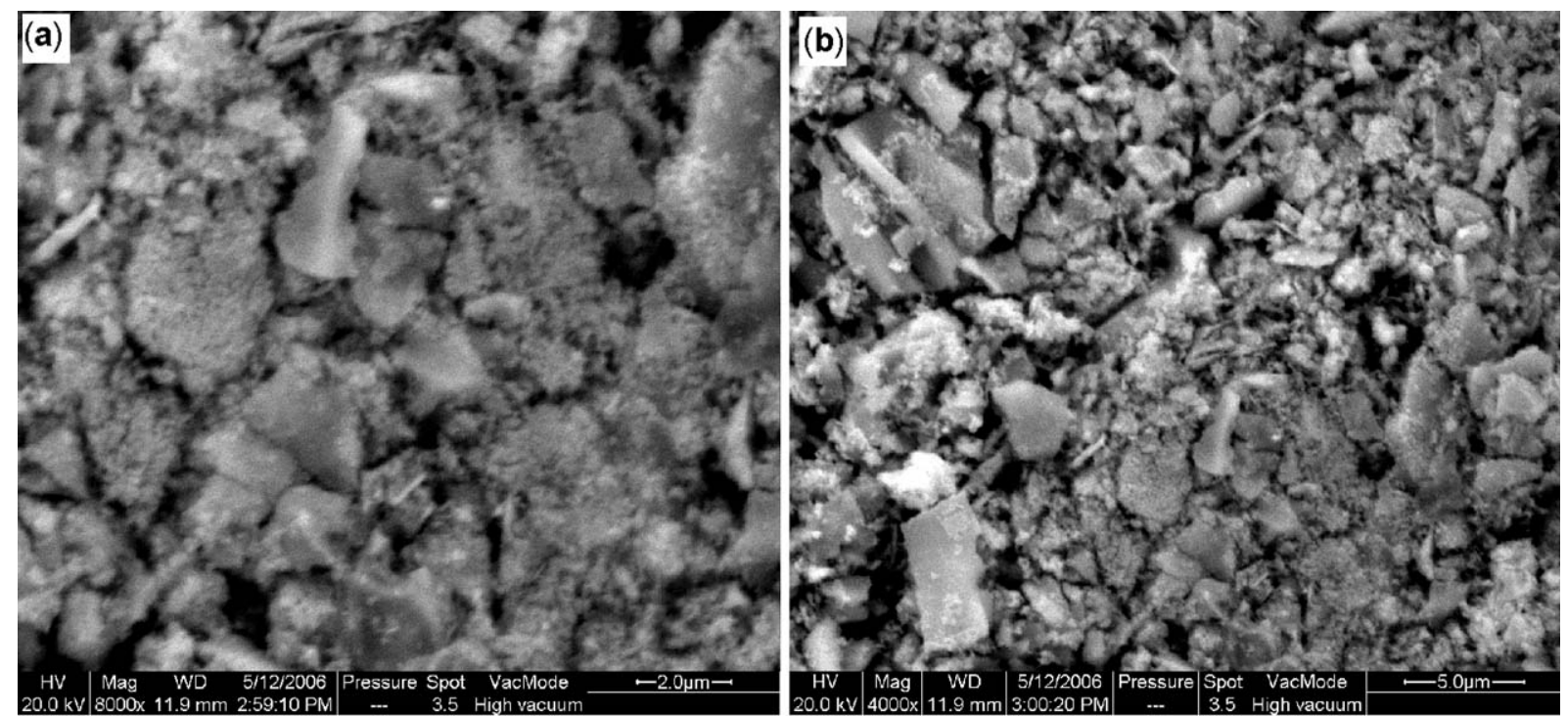

Figure 5. SEM patterns of samples $\mathrm{La}_{0.95} \mathrm{Sr}_{0.05} \mathrm{Ni}_{0.05} \mathrm{Co}_{0.95} \mathrm{O}_{3}$. a. 8000 times; b. 4000 times.

on substitute which implies the surface area of the catalysts is also related to its high porosity.

The principles of the formation of porous and lamella-structural perovskite-type mixed oxides can be explained as follow, ${ }^{11}$ all the organic molecules play a double role: they react with the precursors (metal nitrates), to form complexes with metal cations in aqueous solution, they guarantee a good sol-gel homogeneity, probably avoid the preferential precipitation of ionic species. The porous sponge structure is formed by the combustion of the resulting gel and then porous and lamella structural samples was obtained by the following calcinations at high temperature for several hours.

\subsection{Activity in methane combustion}

The catalytic results of porous $\mathrm{LaCoO}_{3}, \mathrm{La}_{0.95} \mathrm{Sr}_{0.05}$ $\mathrm{Ni}_{0.05} \mathrm{Co}_{0.95} \mathrm{O}_{3}$ and ordinary $\mathrm{LaCoO}_{3}{ }^{10}$ for oxidation of $\mathrm{CH}_{4}$ are summarized in table 1 with 10 and $90 \%$ conversion temperatures $\left(\mathrm{T}_{10}\right.$ and $\left.\mathrm{T}_{90}\right)$. The conversion curves of oxidation of $\mathrm{CH}_{4}$ over these samples are presented in figure 6 . By comparing $T_{10}, T_{90}$ and conversion curves of oxidation of $\mathrm{CH}_{4}$, we find that the catalytic activities of porous $\mathrm{LaCoO}_{3}$ and $\mathrm{La}_{0.95}$ $\mathrm{Sr}_{0.05} \mathrm{Ni}_{0.05} \mathrm{Co}_{0.95} \mathrm{O}_{3}$ for $\mathrm{CH}_{4}$ oxidation are much greater than that of ordinary $\mathrm{LaCoO}_{3}$. The $\mathrm{T}_{10}$ and $\mathrm{T}_{90}$ for porous $\mathrm{La}_{0.95} \mathrm{Sr}_{0.05} \mathrm{Ni}_{0.05} \mathrm{Co}_{0.95} \mathrm{O}_{3}$ was decreased by 161 and $122 \square$, respectively, as compared 


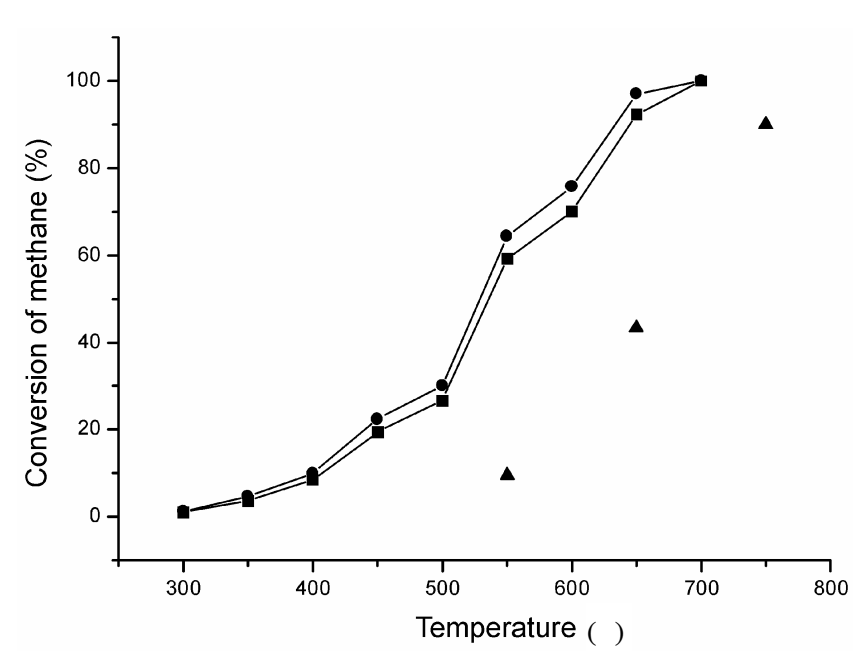

Figure 6. $\mathrm{CH}_{4}$ conversion as a function of temperature over different catalysts. $\bullet$ porous $\mathrm{La}_{0.95} \mathrm{Sr}_{0.05} \mathrm{Ni}_{0.05} \mathrm{Co}_{0.95} \mathrm{O}_{3}$ porous $\mathrm{LaCoO}_{3} \boldsymbol{\Delta}$ Ordinary $\mathrm{LaCoO}_{3}$.

to the ordinary $\mathrm{LaCoO}_{3}$ and, again, partial substitution of lanthanum and cobalt in the porous perovskite with strontium and nickel, respectively, resulted in decreasing $T_{10}$ and $T_{90}$ values by about $19 \square$ as compared to the porous $\mathrm{LaCoO}_{3}$. The enhancement of catalytic activity may attribute to both the higher BET surface of the perovskite used and to the presence of strontium and nickel.

\section{Conclusion}

New catalytic materials based on $\mathrm{LaCoO}_{3}$ and $\mathrm{La}_{0.95}$ $\mathrm{Sr}_{0.05} \mathrm{Ni}_{0.05} \mathrm{Co}_{0.95} \mathrm{O}_{3}$ were developed through a fast and relatively cheap technique. In the technique, the solgel combustion synthesis with citric and organical crosslinking agent is used, to synthesize a catalyst with high specific surface area. The obtained oxide powders were investigated by XRD, SEM and BET measurements. The XRD data for the explored sam- ples showed that all the materials are single phase with more rhombohedral distorted perovskite structure. SEM pictures of $\mathrm{LaCoO}_{3}$ and $\mathrm{La}_{0.95} \mathrm{Sr}_{0.05} \mathrm{Ni}_{0.05}$ $\mathrm{Co}_{0.95} \mathrm{O}_{3}$ composition showed that all the samples obtained from gel precursors have primary fine particles with tendency of lamella structure and high porosity. The catalytic activities of porous samples for $\mathrm{CH}_{4}$ oxidation are much greater than that of ordinary $\mathrm{LaCoO}_{3}$. Therefore, this preparation method is rather simple and the obtained powders are expected for application as catalysts.

\section{Acknowledgements}

The work described above was fully supported by a grant from the Nanchang University and Nanchang Institute of Aeronautical Technology.

\section{References}

1. Batis N H, Elichere P D and Batis H 2005 Appl. Catal. A282 173

2. Uenishi M, Tanaka H, Taniguchi M, Tan I, Sakamoto Y, Matsunaga S, Yokota K and Kobayashi T 2005 Appl. Catal. A296 114

3. Dai H X, He H, Li P H, Gao L Z and Au C 2004 Catal. Today 90231

4. Civera A 2003 Catalsis Taday 8379

5. Belessi V C, Bakas T V and Costa C N 2000 Appl. Catal. B28 13

6. Kwang-Sup S, Cui H X and Kim S D 1999 Catal. Today $\mathbf{4 7} 155$

7. Kenichirou U, Yasuyoshi S and Yoshio M 2005 Thermochimica Acta $\mathbf{4 3 1} 117$

8. Berger D, Fruth V, Jitaru I and Schoonman J 2004 Mater. Lett. $\mathbf{5 8} 2418$

9. Wachowski L 1986 Surf. Coat. Tech. 29303

10. Kucharczyk B and W. Tylus 2004 Catal. Today 90 121

11. Stefania S and Andred C 2004 Chem. Eng. Sci. 59 5091 